\title{
HUBUNGAN STRESS DAN KEBERSIHAN WAJAH TERHADAP KEJADIAN AKNE VULGARIS PADA MAHASISWA KEDOKTERAN UNIVERSITAS MALAHAYATI
}

\author{
Resati Nando Panonsih ${ }^{1}$, Ratna Purwaningrum ${ }^{2}$, Arief Effendi ${ }^{3}$, Wafiq \\ Desarta $^{4}$
}

\author{
1,2,3 Staf Pengajar Fakultas Kedokteran Universitas Malahayati \\ ${ }^{4}$ Program Studi Kedokteran Fakultas Kedokteran Universitas Malahayati \\ Email: desartawafiq@gmail.com
}

\section{ABSTRACT: RELATIONSHIP OF STRESS AND FACE CLEANLINESS TO THE EVENT OF VULGARIS IN MEDICAL STUDENTS OF UNIVERSITAS MALAHAYATI}

Background: Acne vulgaris is a disorder of the sebaceous follicles specifically associated with hair follicles and sebaceous glands are the most common found on the face, chest, and back. Acne vulgaris associated with facial cleanliness and psychological stress.

Objective: This research is aiming to know reletionship of stress and hygiene face of acne vulgaris in malahayati university medical faculty student.

Methods: This study using cross sectional method. Subjects consisted of 324 respondents using questionnaires and physical examination.

Result: Statistical test results are obtained $p$-value $=0,000$ which means $p<a$ (Ho rejected and $\mathrm{Ha}$ accepted) so it can be concluded that there is a stress relationship to the onse of acne vulgaris. An OR score of 26,414, cause stress with respondents had a 26,414 times greater chance of akne vulgaris than those who did not experience stress. Statistical test results are obtained $p$ value $=0.000$ with an $O R$ value of 3,452.

Conclusion: There is a relationship of stress and facial hygiene to the incidence of akne vulgaris in students of the university's medical faculty instead.

Keywords :Acne vulgaris, stress, facial cleanline

\section{INTISARI: HUBUNGAN STRESS DAN KEBERSIHAN WAJAH TERHADAP KEJADIAN AKNE VULGARIS PADA MAHASISWA KEDOKTERAN UNIVERSITAS MALAHAYATI}

Latar belakang :Akne vulgaris adalah suatu kelainan dari folikel sebasea berupa komedo khusus yang berkaitan dengan folikel rambut dan kelenjar sebasea yang tersering dijumpai pada wajah, dada, dan punggung. Akne vulgaris berhubungan dengan kebersihan wajah dan stres psikologis.Selain stres, kebersihan wajah juga merupakan salah satu faktor timbulnya akne vulgaris.

Tujuan :Penelitian ini bertujuan untuk mengetahui hubungan stres dan kebersihan wajah terhadap kerjadian akne vulgaris pada mahasiswa fakultas kedokteran universitas malahayati

Metode :Penelitian ini menggunakan metode crossectional. Subjek penelitian terdiri dari 324 responden dengan menggunakan kusioner dan pemeriksaan fisik pada responden.

Hasil : Hasil uji statistik diperoleh $p$-value $=0,000$ yang berarti $p<a$ (Ho ditolak dan Ha diterima) maka dapat disimpulkan bahwa ada hubungan stress terhadap terjadinya acne vulgaris.Dengan nilai OR 26,414 berarti responden stress memiliki peluang 26,414 kali lebih besar untuk terjadinya akne vulgaris dibandingkan responden yang tidak mengalami stress. Hasil uji statistik diperoleh 
p-value $=0,000$ dengan nilai OR 3,452.

Kesimpulan :Adahubungan stres dan kebersihan wajah terhadap kejadian aknevulgaris pada mahasiswa fakultas kedokteran universitas malahayati

Kata kunci: akne vulgaris, stres, kebersihan wajah

\section{PENDAHULUAN}

Akne vulgaris adalah kondisikulit yang paling umum yang mempengaruhi remaja di seluruh dunia.Menurut studi Global Burden of Disease (GBD), akne vulgaris mempengaruhi $\sim 85 \%$ dari orang dewasa muda berusia 12-25 tahun. Akne vulgaris secara konsisten mewakili tiga kondisi kulit yang paling umum pada populasi umum, seperti yang ditemukan dalam penelitian besar di Inggris, Perancis, dan USA serta dilaporkan pada orang dewasa muda di berbagai negara di seluruh dunia.Produksi androgen selama pubertas menjelaskan, sebagian, mengapa akne vulgaris adalah begitu umum dalam populasi ini tanpa dipengaruhi status sosial ekonomi, bangsa, atau jenis kelamin.

Akne vulgaris merupakan penyakit kulit yang banyak sekali ditemui di Indonesia. Walaupun penyakit ini tidak membahayakan kehidupan tetapi sering terjadi masalah kosmetik pada bentuk akne vulgaris yang berat akibat dari skar yang ditimbulkan dan tidak jarang menjadi keluhan psikologis penderita terhadap lingkungan sosial sekelilingnya bahkan menjadi penyebab kurang percaya diri pada individu tersebut beberapa penelitian yang berhubungan dengan akne vulgaris menyimpulkan bahwa penderita akne vulgaris mengalami masalah fungsional dan emosional sebagai akibat dari penyakitnya

Akne vulgaris berhubungan dengan kondisi kesehatan jiwa dan psikologis remaja contohnya stres psikologis.Stres psikologis merupakan salah satu faktor pemicu timbulnya akne vulgaris atau bahkan memperberat kondisi akne vulgaris yang telah ada.Selain stres, membersihkan wajah juga merupakan faktor yang berhubungan dengan timbulnya akne vulgaris.

Pasien akne vulgaris lebih dari50\% lalai dalam membersihkan wajah dan kejadian ini berhubungan dengan semakin parahnya akne vulgaris, persepsi masyarakat umum percaya bahwa membersihkan kulit akan mengurangi angka kejadian akne vulgaris, meskipun dokter ahli kulit telah memperingati bahwa overwashing dan menggosok berlebihan dapat mengiritasi dan memperburuk akne vulgaris, terutama dapat memperparah folikel sebasea. (Williams et al., 2012).

\section{METODE PENELITIAN}

Desain penelitian merupakan bentuk rancangan yang akan digunakan dalam melakukan prosedur penelitian. Penelitian ini merupakan penelitian kuantitatif, dalam penelitian yang akan dilakukan peneliti menggunakan rancangan analitik dengan metode penelitian crosssectional.Penelitian crosssectional adalah jenis penelitian yangmenekankanpadawaktu pengukuran/observasi data variabel independen dan dependen hanya satu kali, pada satusaat. Instrumen yang digunakan adalah lembar kuesioner perceived StressScale (PSS) 10 yang sebelumnya sudah diterjemahkan ke dalambahasa Indonesia oleh Pin (2011). Perceived Stress Scale adalah 
instrumen psikologi yang 26 paling sering digunakan untuk mengukur tingkat stress dalam individu. Kuensioner ini tidak tergantung pada situasi tertentu. PSS juga sensitif terhadap kejadian yang tidak sedang terjadi maupun yang sedang berjalan dalam kehidupan sehari-hari (El-Masry et al., 2013).Perceived Stress Scale telah dinyatakan valid dan reliable dengan nilai koefisien Cronbach Alpha sebesar 0,85 (Untuk PSS-10 dalam bahasa Indonesia, telah diuji danmemiliki nilai koefesien Cronbach Alpha sebesar 0,96 (Pin, 2011) . PSS-10 adalah self report questionnaire yang terdiri dari 10 pertanyaan dan dapat mengevaluasi tingkat stress satu bulan yang lalu dalam kehidupan subjek penelitian. Setiap pertanyaan dapat bernilai 0 (tidak pernah) sampai dengan 4 (sangat sering).

Alur penelitian yang harus dilakukan yaitu: Membuat surat presurvey, membuat surat izin penelitian, permintaan persetujuan sebagai responden pada mahasiswa Fakultas Kedokteran Universitas Malahayati, menyebarkan lembar kuesioner, pengisian kuesioner oleh responden dan melakukan dokumentasi oleh peneliti, pemilihan responden berdasarkan kriteria inklusi, pengumpulan data responden, pengolahan data.

Pengolahan Data Data Primer
Yaitu data yang diperoleh dari jawaban responden tehadap pertanyaan dalam kuesioner dan hasil pengamatan langsung oleh peneliti meliputi aspek pengetahuan tentang Akne Vulgaris.

Data Sekunder Yaitu data yang mendukung kelengkapan data primer yang dikumpulkan dari sumber- sumber yang telah ada kelengkapan dokumentasi dalam kejadian Akne Vulgaris pada Mahasiswa Kedokteran Universitas Malahayati tahun 2020.

Analisis Univariat ini bertujuan untuk menjelaskan atau mendeskripsikan karakteristik masing masing variabel yang di teliti. Data univariat ini terdisi atas usia,jenis kelamin, responden stres, responden akne vulgaris, responden pengguna pembersih wajah dan frekuensi membersihkan wajah.

Analisis bivariat ini bertujuan untuk mencari hubungan stres dan kebersihan wajah terhadap akne vulgaris di mahasiwa Fakultas Kedokteran Universitas Malahayati. Pada analisis bivariat ini menggunakan tabel tabulasi silang yang dimana untuk menganalisis hubungan antara dua variabel atau lebih. Pada uji hubungan antara stres dan kebersihan akne vulgaris memakai uji statistik chisquare. Penelitian ini sudah dilakukan uji layak etik dengan no surat uji laik etik No.1182/EC/KEPK- 
HASIL

Analisis Univariat

Tabel 1

Distribusi Berdasarkan Umur

\begin{tabular}{lcc}
\hline Umur & Frekuensi & Persentase(\%) \\
\hline$<21$ & 158 & $48,8 \%$ \\
Tahun & 166 & $51,2 \%$ \\
$\geq 21$ & & \\
Tahun & & \\
& & $\mathbf{1 0 0 , 0 \%}$ \\
\hline
\end{tabular}

Berdasarkan Tabel 1 diketahui sebanyak 158 orang $(48,8 \%)$ dan pada bahwa dari 324 sampel di dapatkan usia $\geq 20$ tahun sebanyak 166 orang sampel pada usia $\leq 21$ tahun $(51,2 \%)$.

Tabel 2

Distribusi Berdasarkan Jenis Kelamin

\begin{tabular}{ccc}
\hline $\begin{array}{c}\text { Jenis } \\
\text { Kelamin }\end{array}$ & Frekuensi & Persentase(\%) \\
\hline Laki-Laki & 157 & $48,5 \%$ \\
Perempuan & 167 & $51,5 \%$ \\
\hline Total & $\mathbf{3 2 4}$ & $\mathbf{1 0 0 , 0 \%}$ \\
\hline
\end{tabular}

Berdasarkan Tabel 2 diketahui bahwa dari 324 sampel sebagian besar responden perempuan sebanyak 167 orang $\mathbf{( 5 1 . 5 \% )}$ sedangkan pada laki-laki sebanyak 157 orang $(48,5 \%)$.

Tabel 3

Distribusi Berdasarkan Stress

\begin{tabular}{lcc}
\hline Stress & Frekuensi & Persentase \\
\hline Tidak & 191 & $59,0 \%$ \\
Stress & 133 & $41,0 \%$ \\
Stress & & \\
\hline Total & $\mathbf{3 2 4}$ & $\mathbf{1 0 0 , 0 \%}$ \\
\hline
\end{tabular}

Berdasarkan Tabel 3 diketahui sedangkan pada responden yanng bahwa sebagian besar responden mengalami stress sebanyak 133 yang tidak mengalalmi stress orang $(41,0 \%)$. sebanyak 191 orang $(59,0 \%)$

Tabel 4

Distribusi Berdasarkan Penggunaan Pembersih Wajah

\begin{tabular}{lcc}
\hline $\begin{array}{c}\text { Pengguna } \\
\text { Pembersih Wajah }\end{array}$ & Frekuensi & Persentase \\
\hline Tidak & 69 & $21,3 \%$ \\
menggunakan PW & 255 & $78,7 \%$ \\
\hline \multicolumn{1}{c}{ Total } & 324 & $100,0 \%$ \\
\hline
\end{tabular}


Berdasarkan Tabel 4 diketahui dari 324 responden yang mengunakan pembersih wajah sebanyak 255 orang $(78,7 \%)$ lebih banyak daripada yang tidak menggunakan pembersih wajah sebanyak 69 orang $(21,3 \%)$.

\section{Analisis Bivariat}

Tabel 5

Hubungan Stress terhadap kejadian Acne Vulgaris

\begin{tabular}{|c|c|c|c|c|c|c|c|c|}
\hline \multirow{3}{*}{$\begin{array}{l}\text { Akne } \\
\text { Vulgaris }\end{array}$} & \multicolumn{6}{|c|}{ Stress } & \multirow{3}{*}{$\begin{array}{c}P- \\
\text { Value }\end{array}$} & \multirow{3}{*}{$\begin{array}{c}\text { OR } \\
(\mathrm{Cl} \\
96 \%)\end{array}$} \\
\hline & \multicolumn{2}{|c|}{ Stress } & \multicolumn{2}{|c|}{ Tidak Stress } & \multicolumn{2}{|c|}{ Total } & & \\
\hline & $\mathbf{N}$ & $\mathrm{P}(\%)$ & $\mathbf{N}$ & $\mathrm{P}(\%)$ & $\mathbf{N}$ & $P(\%)$ & & \\
\hline AV & 129 & $55,1 \%$ & 105 & $44,9 \%$ & 234 & $100 \%$ & 0,000 & 26,414 \\
\hline Tidak AV & 86 & $95,6 \%$ & 4 & $4,4 \%$ & 90 & $100 \%$ & & $\begin{array}{l}(9,382- \\
74,365)\end{array}$ \\
\hline Total & 133 & $41,0 \%$ & 191 & $59,0 \%$ & 324 & $100 \%$ & & \\
\hline
\end{tabular}

Berdasarkan Tabel 5 diatas dapat dilihat dari 324 responden acne vulgaris yang mengalami stress terdapat 129 orang $(55,1 \%)$ dan akne vulgaris yang tidak mengalami stres terdapat 105 orang (44,9\%). Sedangkan sebanyak 86 orang $(95,6 \%)$ tidak mengalami acne vulgaris dan sebanyak 4 orang $(4,4 \%)$ tidak mengalami stress.

Hasil uji statistik diperoleh p- value $=0,000$ yang berarti $\mathrm{p}<\mathrm{a}(\mathrm{Ho}$ ditolak dan Ha diterima) maka dapat disimpulkan bahwa ada hubungan stress terhadap terjadinya acne vulgaris. Dengan nilai OR 26,414 berarti responden stress memiliki peluang 26,414 kali lebih besar untuk terjadinya akne vulgaris dibandingkan responden yang tidak mengalami stress.

Tabel 6 Hubungan Pengguna Kebersihan Wajah Terhadap kejadian Acne Vulgaris

\begin{tabular}{|c|c|c|c|c|c|c|c|c|}
\hline \multirow{3}{*}{$\begin{array}{l}\text { Akne } \\
\text { Vulgaris }\end{array}$} & \multicolumn{6}{|c|}{ Pengguna Pembersih Wajah } & & \multirow[b]{2}{*}{ OR } \\
\hline & \multicolumn{2}{|c|}{ lya } & \multicolumn{2}{|c|}{ Tidak } & \multicolumn{2}{|c|}{ Total } & \multirow[b]{2}{*}{$\begin{array}{c}\text { P- } \\
\text { Value }\end{array}$} & \\
\hline & $\mathbf{N}$ & $\mathrm{P}(\%)$ & $\mathbf{N}$ & $\mathrm{P}(\%)$ & $\mathbf{N}$ & $\mathrm{P}(\%)$ & & $(\mathrm{Cl} 95 \%)$ \\
\hline AV & 199 & $85,0 \%$ & 35 & $15,0 \%$ & 234 & $72,2 \%$ & 0,000 & 3,452 \\
\hline Tidak AV & 34 & $37,8 \%$ & 56 & $62,2 \%$ & 90 & $27,8 \%$ & & $\begin{array}{c}(1,977- \\
6,027)\end{array}$ \\
\hline Total & 69 & $21,3 \%$ & 255 & $78,7 \%$ & 324 & $100 \%$ & & \\
\hline
\end{tabular}


Berdasarkan Tabel 6 diatas dari 324 responden yang mengalami akne vulgaris sebanyak 35 orang $(15,0 \%)$ dan tidak menggunakan pembersih wajah. Terdapat 199 orang $(85,0 \%)$ menggunakan pembersih wajah dan mengalami akne vulgaris, sebanyak 34 orang $(37,8 \%)$ tidak mengalami akne vulgaris dan menggunakan pembersih wajah, terdapat 56 orang $(62,2 \%)$ tidak menggunakan pembersih wajah dan tidak mengalami akne vulgaris.

\section{PEMBAHASAN}

Usia pada penelitian ini yaitu 17 tahun sampai dengan 25 tahun, dimana usia tersebut termasuk kategori usia remaja akhir Depkes RI (2009). Distribusi sampel berdasarkan usia dapat dilihat pada tabel 4.1 diketahui bahwa dari 324 sampel di dapatkan sampel yang terjadi pada usia 19 tahun sampai dengan 20 tahun sebanyak 158 orang $(48,8 \%)$, dan pada usia 21 tahun sampai dengan 25 tahun sebanyak 166 orang $(51,2 \%)$. Dapat dilihat bahwa prevalensi umur pada usia 21 tahun sampai dengan 25 tahun lebih tinggi dari pada usia 19 tahun sampai dengan 20 tahun.

Hal ini disebabkan oleh beberapa faktor yakni, prevalensi mahasiswa yang menderita stress dan akne vulgaris memang lebih tinggi pada kelompok tersebut atau saat pengambilan sampel lebih banyak mahasiswa dari kelompok umur tersebut yang hadir saat penelitian dilaksanakan .

Diketahui bahwa dari 324 sampel sebagian besar responden perempuan sebanyak 167 orang (51.5\%) sedangkan pada laki-laki sebanyak 157 orang (48,5\%). Dari hasil data penelitian tersebut didapat akne vulgaris lebih banyak terjadi pada wanita dari pada pria.

Pada 60-70\% wanita, lesi akne menjadi lebih aktif kurang lebih satu
Hasil uji statistik diperoleh pvalue $=0,000$ yang berarti $\mathrm{p}<\mathrm{a}(\mathrm{Ho}$ ditolak dan Ha diterima) maka dapat disimpulkan bahwa ada hubungan Penggunaan pembersih wajah terhadap terjadinya acne vulgaris.Dengan nilai OR 3,452 berarti responden stress memiliki peluang 3,452 kali lebih besar untuk terjadinya akne vulgaris dibandingkan responden yang menggunakan pembersih wajah.

minggu sebelum haid karena hormon progesteron. Estogen dalam keadaan tertentu seperti pada saat selesai masa haid dapat menekan pertumbuhan akne vulgaris. Karena pada saat masa haid selesai terjadi peningkatan kadar hormon estrogen. Peningkatan hormon androgen dan progesteron secara tidak langsung meningkakan insidensi timbulnya akne vulgaris.sedangkan peningkatan hormon estrogen dapat menurunkan timbulnya akne vulgaris

Diketahui bahwa sebagian besar
responden yang tidak stress
sebanyak 191 orang $(59,0 \%)$
sedangkan pada responden yanng
mengalami stress sebanyak 133
orang (41,0\%).lebih tinggi terjadi
pada mahasiswa yang tidak
mengalami stress.
Pikiran negatif dapat
mengakibatkan patologis dalam
perubahan nerubahan-
fisik.Pikiran negatif ini dapat
berkembang menjadi kepercayaan
yang salah yang tidak dapat diubah
sehingga emosi menjadi beku dalam
keadaan negatif dan tubuh
memasuki simpatis kronis yang
disebut stres. Sebagai hasilnya,
mekanisme homeostasis berlangsung
gagal dan timbul akne vulgaris
(Wasitaatmadja, 2002; Harahap,
2000).
Dari 324 responden yang
mengunakan pembersih wajah


sebanyak 255 orang $(78,7 \%)$ lebih banyak dari pada yang tidak menggunakan pembersih wajah sebanyak 69 orang $(21,3 \%)$.

Tujuan pembersihan wajah adalah menghilangkan sel-sel kulit mati dan kelebihan minyak, keringat, kotoran dan sisa kosmetik. Bahan dasar pembersih wajah ada tiga, yaitu :

Bahan dasar air dan alkohol : face tonic, penyegar

Bahan dasar minyak : krim pembersih, susu pembersih

Bahan dasar padat : masker

Sifat krim pembersih yang baik adalah bersifat lunak, mudah diratakan, tidak terlalu berlemak dan sisa krim tidak mengental setelah pemakaian. Untuk sabun pembersih yang ideal adalah soapless soap yang merupakan suatu. detergen sintetik (synthetic detergent $=$ syndet

\section{KESIMPULAN}

Kesimpulan yang didapat setelah dilakukan penelitian adalah:

\section{DAFTAR PUSTAKA}

Adhi, D., Hamzah, M., Aisyah, S. (2008). Akne vulgaris. Dalam: Ilmu Penyakit Kulit Dan Kelamin, Edisi 5, Jakarta: Fakultas Kedokteran Universitas Indonesia.

Al-Hoqail, I. A. (2013). Knowledge, beliefs and perception of youth to ward acne vulgaris, Saudi Med Journal. Available fromhttp://www.smj.org.sa/r eprint/352/14/1463

Arikunto, S. (2007). Analisis Data Penelitian Deskriptif. Dalam: Arikunto, S., ed. Manajemen Penelitian. Jakarta: PT RINEKA CIPTA, 262-296.
1. Hubungan antara Penggunaan pembersihan wajah dengan kejadian akne vulgaris pada mahasiswa Fakultas Kedokteran Universitas Malahayatiangkatan 2017 didapatkan $p=0,000$ dan $O R=3,452$ yang artinya terdapathubungan yang signifikan.

2. Hubungan antara stress dengan kejadian akne vulgaris pada mahasiswa Fakultas Kedokteran Universitas Malahayati angkatan 2017 didapatkan $\mathrm{p}=0,001$ danOR $=$ 26,414 yang artinya terdapat hubungan yang signifikan.

\section{SARAN}

1. Bagir esponden, mengurangikondisi yang dapat menimbulkan stress dan senantiasa menjaga kebersihan wajah guna mencegah akne vulgaris.

2. Bagi peneliti selanjutnya, perlu dilakukan penelitian lanjut mengenai faktor - faktor lain yang mempengaruhi timbulnya akne vulgaris.

Bhat, R. M., Sameer, M. K. dan Ganaraja, B. (2011). Eustress in Education:Analysis of the Perceived Stress Score (PSS) and Blood Pressure (BP) during Examinations in Medical Students. Journal of Clinical andDiagnostic Research, 5(7), 331-1335.

Brown, G.R. and Burns, T. (2015). Akne, Erupsi, Akneiformis, dan Rosasea. Lecture Notes : Dermatology . Ed8. Jakarta : Erlangga, pp: 55-65

Choi JM. Lew VK, Kimbal AB. (2016). A single-blinded, randomized, controled clinical tial evaluating the efect of face washing on acne vulgaris.PediatrDermatol. 
Cordain, L., Hurtado, M., Eaton, S.B. (2002).Acne vulgaris: A disease of Western Draelos JD. 2009. Skin care maintenance product. Dalam Atlas of cosmetic dermatology, Churcill Livingston. 77-82

Depkes RI. (2009). Kategori Umur Menurut Depkes. Available form

https: / /yhantiaritra.wordpres s.com/2015/06/03/kategoriumur-menurut-depkes /

Drealos, Z. D. (200. Optimal Skin Care for Aesthetic Patients; Tropical Products to Restore and Maintain healthy Skin. Cos Derm:22:2-8

El-Masry, R., Ghreiz, S. M., Helal, R. M., Audeh, A. M. dan Shams, T. (2013). Perceived Stress and Burnout among Medical Students during the Clinical Period of Their Education.

Folkman, L., et al. (2011). Psyhososial impact of acne vulgaris.evaluation

oftherelation between a change in clinical acne severity and psychosocial state. Dermatology.2001: 203(2):124-30.

Gunawan, B. (2007). Stres dan Sistem Imun Tubuh :SuatuPendekatan

Psikoneuroimunologi . Cermin DuniaKedokteran. 154 : 13-16.

Kim BY, Choi J.W. (2013). Sbum, Acne, skin elasticity, and gender difference- wichis the majorinfluencing factor for facial pores. 45-53
Latifah, F., dan Tranggono, R.I. (2007). Buku Pegangan IImu Pengetahuan Kosmetik. Jakarta: PT Gramedia Pusaka Utama. Halaman 7, 21

Maibach A, Baran HI, Shai R. (2009). Handbook of Cosmetic Skin Care. 2nd ed United States of America; .

Nami, U. (2009). Hubungan Tingkat Stress Dan Kebersihan Diri dengan Akne Vulgaris.

Sugiyono. (2007). Metode Penelitian Kuantitatif Kualitatif dan $R \& D$. Bandung:Alfabeta

Wasitaadmadja Syarif M. (2008). Akne vulgaris, Rosasea, Rinofima.Dalam : Ilmu Penyakit Kulit dan Kelamin. Jakarta: Penerbit UI, Hal 231365.

Wasitaatmadja, S. (2002), Akne, Erupsi Akneiformis, Rosasea, Rinofema.

Williams, H. C., Dellavalle P. R., Garner, S. (2012). Acne Vulgaris. Lancet;379: 361-72

Zaenglein A.L., Graber E.M., Thiboutot D.M. (2012). Acne vulgaris and acneiform eruptions. Dalam: Wolff $K$, Goldsmith LA, Katz SI, Gilchrest BA, Paller AS, sLeffel $D J$, Fitzpatrick Dermatology in general medicine. Edisi ke-8. New York: McGraw Hill.

Zouboulis, Bohm M . (2010). Neuroendocrine regulation of sebocytes-a pathogenetic link between stress and acne, Zouboulis ed, Dermatol. Blackwell Munksgaard,31-35. 